ció amb els estudis crítics sobre la modernitat i la postmodernitat. Recentment, Abraham Mohino ha editat quaranta-tres entrevistes a Mercè Rodoreda en les quals l'escriptora reflexiona sobre el fet literari (Mercè Rodoreda. Entrevistes, publicat per la Fundació Mercè Rodoreda de l'Institut d'Estudis Catalans). Els autors de les obres analitzades a La literatura davant del mirall reflexionen sobre la literatura a través dels textos literaris i utilitzen la ironia per qüestionar l'existència d'una barrera que separi la realitat de la ficció, l'autobiografia i la Història de la trama. Donar a conèixer la concepció dels autors sobre els escrits propis i la literatura en general, ja sigui a partir de l'epitext, ja sigui a partir de l'obra literària, n'enriqueix la lectura, l'anàlisi i, en definitiva, genera noves reflexions i continua el diàleg literari amb les noves generacions de lectors, autors i crítics.

\title{
Democratic Policies for Language Revitalisation: the Case of Catalan
}

Albert Turull

Universitat de Lleida, Departament de Filologia Catalana i Comunicació turull@filcat.udl.cat

Boix-Fuster, Emili i Miquel Strubell, Democratic Policies for Language Revitalisation: the Case of Catalan, Houndmills: Palgrave MacMillan, 2011; «Palgrave Studies in Minority Languages and Communities».

L'aparició d'aquest llibre ha estat (fou, l'any 2011) evidentment oportuna després hi tornarem-, però no sols això: ha estat, i és, també important. Sobretot per dues raons: perquè omple un buit en un aspecte qualitativament important —el del coneixement del cas català en l'àmbit internacional - i perquè és, en si mateix, una aportació valuosa i significativa per a la ja força nodrida bibliografia sociolingüística catalana.

Amb una voluntat explícitament col-laborativa, els responsables del llibre, Miquel Strubell i Emili Boix-Fuster — dos noms plenament consolidats dins del que podem considerar la segona generació de sociolingüistes catalans-, hi han aplegat una sèrie de contribucions que, malgrat alguna inevitable reiteració, resulten certament complementàries entre si, de manera que se'ns presenta un panorama ben complet de l'actual situació de la llengua catalana en termes de vitalitat sociolingüística i d'estatus polític i legal. Com que, a més, les diferents aportacions, totes elles d'autors de reconegut prestigi (i en aquest cas de dues generacions diferents: la dels mateixos curadors $i$ ja la següent), tenen un nivell d'aprofundiment $\mathrm{i}$ un rigor envejables, es pot ben afirmar que aquest llibre - a cavall entre el manual i l'estudi monogràfic - figura des del mateix moment de la seva aparició, per mèrits propis, dins del reduït grup de les referències principals actuals en 
matèria de sociolingüística catalana. Dit així sembla poc (o molt: seria qüestió d'apreciacions subjectives), però el fet és que tothom que ara mateix vulgui conèixer amb una certa profunditat, $i$ alhora una visió de conjunt, quin és l'estat real de la llengua catalana, ha de consultar necessàriament aquest llibre; no fer-ho seria una mancança bibliogràfica difícilment justificable. I això val tant per a la comunitat internacional - a qui en principi sembla anar adreçat el volum, atesa la llengua i l'editorial de publicació- com per a la mateixa comunitat catalana, on, com és públic i notori, l'interès per la matèria lingüística (i per la més específicament sociolingüística) gaudeix d'una potència i d'una constància que són l'enveja, i la sorpresa, de no pocs dels nostres colllegues d'arreu del món.

Obre el volum una introducció dels mateixos responsables de l'edició, Miquel Strubell i Emili Boix-Fuster, que no és pas la simple introducció típica d'altres publicacions, merament de benvinguda o de presentació dels continguts ulteriors (cosa que tanmateix no deixa de fer), sinó un text ampli i ben travat, on s'exposen ja alguns dels arguments bàsics que, com és lògic, recorreran la resta de les pàgines, de forma transversal entre uns autors $\mathrm{i}$ uns altres, uns temes i uns altres; per exemple, s'hi situen en el seu context polític les diferències notòries que presenta el tractament de la situació lingüística en uns territoris o en uns altres, fins al punt que un darrer paràgraf, redactat ja durant la fase d'edició del llibre, ha d'al-ludir a la famosa sentència del Tribunal Constitucional espanyol, de juliol de 2010, sobre (o contra) l'Estatut d'Autonomia de Catalunya, que tan evidents conseqüències jurídiques ha comportat després pel que fa a la política lingüística (i a la no lingüística, però aquest seria un altre tema). Aquesta Introduction, per tant, esdevé un altre dels capítols notables del llibre, tan recomanable i imprescindible com qualsevol dels següents.

Aquestes diferents contribucions — vuit en total, a banda de l'esmentada introducció- han estat encarregades, com dèiem adés, a sengles especialistes en la matèria, tots ells de l'àmbit lingüístic català i tots ells, naturalment, amb un prestigi acadèmic — per norma general en el si de la Universitat i/o de l'IEC- que fa que el resultat sigui perfectament homologable a nivell internacional —com no podia ser altrament, més que mai, en un llibre com aquest—i, a més a més, complet i complementari.

En primer lloc, Miquel Àngel Pradilla, a «La Catalanofonia. A Community in Search of Linguistic Normality», presenta al lector -en aquest cas sobretot a l'estranger, per bé que moltes de les dades que aporta faran profit a més d'un lector català- les dades fonamentals sobre l'objecte del llibre, que no és sols la llengua catalana en termes generals, sinó més específicament la comunitat lingüística catalana: això que ja al títol del capítol apareix mitjançant una expressió (no traduïda), Catalanofonia, que si bé entre nosaltres mateixos no està gaire estesa, resulta segurament prou comprensible — per la via de l'homologació amb la Francophonie, per exemple - a lectors d'arreu. D'alguna manera, doncs, aquest primer capítol d'encàrrec gairebé és una (altra) introducció, si bé més sistemàtica i detallada que la prèvia, i no és gens casual, vist això, que sigui justament el text 
que obre foc un cop entrats definitivament en matèria. Tanmateix, Pradilla no es limita a exposar (i comentar) dades de tipus demolingüístic, geolingüístic, històric, etc., sinó que, ampliant el capítol fins convertir-lo en el més extens del volum (una quarantena de pàgines), ofereix també un ampli resum sobre la planificació lingüística en aquest àmbit, mitjançant la clàssica dualitat entre corpus planning $\mathrm{i}$ status planning, i en cada cas recorrent la línia que va des dels precedents històrics i culturals — la koiné medieval, per exemple - fins als conflictes actuals que, des d'una òptica inevitablement decantada vers la realitat valenciana, tan bé ha estudiat aquest autor al llarg dels darrers temps.

A continuació, i entroncant de forma ben escaient amb un dels aspectes apuntats tant per Pradilla com, abans, per Strubell i Boix, trobem el capítol que signen Jaume Vernet i Eva Pons, reconegudes autoritats en el nostre dret lingüístic. I aquest és, naturalment, el tema de la seva aportació: «The Legal Systems of the Catalan Language», on van desgranant en termes extremament precisos (i probablement amb alguna sorpresa per als llecs, ja siguin estrangers o autòctons), les diferents formulacions - certament diferents-que es donen pel que fa al tractament de la llengua i de la seva oficialitat (en general, com sabem, cooficialitat o simplement no oficialitat) en els diversos territoris en què al llarg de la història ha anat quedant dividida l'àrea lingüística pròpia del català: en quatre estats de l'occident europeu i, dins de l'Estat espanyol, en cinc comunitats autònomes (comptant-hi Múrcia, per la singular zona del Carxe, que tants llibres i manuals - però no aquest - passen per alt). Es tracta, en definitiva, d'un panorama global, convenientment desglossat per regions, que aconsegueix de reunir en un sol document la informació bàsica sobre l'estat legal de la llengua catalana, sense llacunes significatives ni sortides de to; l'única llàstima — no en podríem dir defecte, perquè no és pas atribuïble als autors, i ni tan sols als editorsés que, en aquesta matèria en particular, el temps ha corregut molt de pressa: tant, que són uns quants els punts en què aquesta informació ha quedat una mica desfasada d'ençà de la redacció del capítol i de la publicació del llibre (per exemple, és clar que no recull —no podia recollir- la sentència del Tribunal Constitucional de 2010 a què ens hem referit adés, ni les darreres escomeses legals contra la normalitat de la llengua catalana que els anys següents han tingut lloc no sols a València o des del govern espanyol —aquestes venien ja de lluny- sinó ara, també, molt significativament, des dels governs populars d'Aragó i de les Balears: grotesca denominació lapao, decret de trilingüisme per acabar amb la immersió a les escoles, etc.).

El quart capítol, signat per l'actual president de la Secció Filològica de l'IEC, Isidor Marí, aborda un aspecte que, d'alguna manera, sempre és tractat dins dels estudis i de les provisions sobre l'ús i l'estatus de la llengua, però que en general no sol rebre, com aquí, l'atenció d'un text específic; es tracta de l'ús en les relacions públic-privat, o més en concret entre les autoritats i la ciutadania. Així doncs, Marí, a «Policies Governing the Use of Languages in Relations between the Autorities and the Public», repassa els detalls relatius a aquest aspecte, $\mathrm{i}$ ho fa, un cop 
més, recorrent els diferents territoris, en funció de la situació legal d'oficialitat única (Andorra), cooficialitat o no oficialitat del català. D’aquesta manera es fa patent com aquest capítol significa un aprofundiment temàtic de l'anterior, ja que al capdavall és en les disposicions legals que es regula (o no) l'ús de la llengua per part de les administracions, i també les possibilitats d'ús que aquestes ofereixen a la població, que no cal dir que són altament variables. Assenyalem encara que, en aquest recorregut, Marí no sols no s'oblida tampoc del Carxe ni de cap zona de l'àrea lingüística catalana, sinó que inclou un bon paràgraf sobre l'occità amb motiu de la Vall d'Aran (fins arribar a la generalització de la cooficialitat de l'occità en l'Estatut de 2006, però ja no a la llei específica de quatre anys després) i, fins i tot, sengles subcapítols, abans de cloure una aportació completa i valuosa, a la situació de les relacions en matèria de llengua amb les administracions espanyoles (inclosa la de justícia) i a la que afecta determinades institucions supranacionals (Consell d'Europa, Unió Europea).

Seguidament, F. Xavier Vila se centra en un altre aspecte prou concret - però tan transcendent per a la vitalitat i el futur de la nostra llengua-com és la política lingüística educativa: «Language-in-Education Policy». Val a dir que es tracta d'un article molt complet (per bé que lògicament condicionat pel nombre de pàgines), en el sentit que no es limita a descriure els models lingüístics escolars dels quatre territoris on n'és el cas (Catalunya, Illes Balears, País Valencià, Franja de Ponent) sinó que, prèviament, parteix d'una interessant síntesi històrica que remunta fins a l'edat moderna i desemboca en la constitució de 1978 (passant per la de 1931); i no sols això, sinó que, després de l'explicació d'aquells models per territoris (lamentablement desactualitzada ja, atès que descriu un estat de les coses de vers 2007 que, com sabem, després ha estat notablement alterat), destina encara uns paràgrafs a l'acolliment d'infants al-loglots, a l'educació superior i a l'ensenyament d'adults.

El següent capítol està dedicat a les polítiques en favor d'actituds positives envers la llengua i, per tant, del seu ús («Policies Promoting the Use of Catalan in Oral Communications and to Improve Attitudes towards the Language»), i ve signat en aquest cas per tres autors, pertanyents (sembla que no pas per casualitat) als tres territoris principals del domini lingüístic: l'illenc Joan Melià, el valencià Brauli Montoya i, per part del Principat, un dels mateixos curadors del volum, Emili Boix-Fuster. Després d'un subcapítol dedicat a explicar l'arrel i les concrecions del problema (realment útil, sens dubte, per als lectors forans), els autors se centren a descriure les diverses campanyes, des de la Norma fins a la Queta i més ençà, que han dut a terme els governs autònoms en un moment o un altre (és a dir, sovint de forma paral-lela a determinats canvis polítics o a campanyes d'intencionalitat força descriptible). A les conclusions, en fi, es pregunten per què han hagut de ser tan insistents i recurrents les campanyes d'aquesta mena: és que potser la clau de volta es troba en un altre àmbit (el legal i polític, per exemple)?...

Semblantment, els capítols setè i vuitè se centren en dues branques concretes de la política lingüística; dues d'importants entre aquelles que, per llur naturalesa 
social, es troben a cavall entre l'esfera pública i la privada: els mitjans de comunicació i l'àmbit empresarial $i$ comercial. En el primer, un especialista tan reconegut (i amb tant de recorregut, ja) com Josep Gifreu desgrana no sols el marc històric i legal en què tingué lloc el desplegament de diversos mitjans de masses en l'àmbit lingüístic català (o fora d'ell, com les televisions privades), sinó que dedica també uns paràgrafs a les polítiques lingüístiques pròpies d'aquests mitjans; en acabat, encara un darrer subcapítol de l'aportació de Gifreu està destinat a analitzar, amb una intel-ligent visió de conjunt, la realitat actual (de vers 2007) de l'espai comunicatiu català, amb unes conclusions que, com no podia ser altrament, posen en relleu tant el balanç positiu del que l'existència i la dinàmica d'aquests mitjans de comunicació catalans han comportat, com, en l'altre plat de la balança, les seves mancances i, sobretot, les del seu context polític, que en darrera instància deixen en l'aire la solvència d'un futur que no està pas assegurat. En el següent capítol, Albert Branchadell $\mathrm{i}$ Joan Melià s'ocupen d'un altre dels àmbits a cavall entre l'esfera pública $\mathrm{i}$ la privada en què un balanç és obligatòriament dual (i en aquest cas particularment crític, ja des del títol, on es parla de «Ineffectiveness»): el del món del comerç i l'empresa. En aquesta ocasió, els autors, tot i desgranar també el panorama en els diferents territoris (en la mesura que, com és prou obvi, hi ha diferents legislacions i diferents dinàmiques sociolingüístiques), estructuren una part del seu text —el que dediquen al Principat - a partir d'una cronologia, en la qual les dates de 1990 (reorientació de la política lingüística, amb Miquel Reniu, vers l'ús social del català) i 2003 (canvi de govern després de vint-i-tres anys de pujolisme) esdevenen uns punts d'inflexió - algú podria dir que discutibles pel que fa a la tria- que tanmateix ajuden a comprendre l'evolució dels fets en aquest àmbit, el comercial i econòmic, que massa sovint ha estat desatès no sols en les descripcions sociolingüístiques sobre el català sinó fins i tot dins les preocupacions preferents de les autoritats competents en la matèria.

Finalment, el darrer capítol del volum reprèn, com tancant-ne el cercle, un dels punts que havia inclòs Miquel Àngel Pradilla en el seu extens treball introductori: en aquesta cloenda la seva autora, Elena Heidepriem Olazábal, té per missió oferir un panorama de les contribucions a la política i la planificació lingüístiques des de l'àmbit català o, per dir-ho amb la mateixa expressió anglesa que hi fa de títol, «An Overview of Catalan Research into Language Policy and Planning». No es tracta, però, d'un resum històric, ni pretén aproximar-se a un sumari exhaustiu de tot el que s'ha fet $i$ escrit en aquest camp des de la nostra comunitat lingüística des de fa dècades (si aquest hagués estat l'objectiu, caldria retraureli dotzenes d'absències), sinó que, centrant-se en unes determinades aportacions (per exemple, en el camp de la política lingüística educativa, sobretot dues: Argelaguet i Münch), va desgranant allò que considera essencial de cada tema (educació, justícia, esfera socioeconòmica, etc.) a fi d'oferir al lector una mena de guia o resum, que, bo i resultar ben pràctic en diversos punts, no pot sinó deixar-nos la impressió d'una certa reiteració, o circularitat, o manca de coordinació amb la resta de capítols del llibre. 
Malgrat això - malgrat el caràcter potser excessivament global de les primeres i de la darrera aportació, que contrasta amb l'acotada especificitat de la resta-, el cert és que, vist el llibre com una obra unitària, com un conjunt bastit a partir de la suma dels seus diferents capítols, no es pot sinó confirmar - i celebrar- que aquesta suma sigui realment complementària i, sobretot, que el resultat global se situï a l'alçada de les expectatives que una publicació com aquesta és normal que hagués generat.

Tot llibre, però, té també defectes. En aquest cas, per fortuna, són pocs i no gens greus. En podem assenyalar si més no de dos tipus. Uns, que resulten molt difícils d'evitar en un llibre de múltiple autoria, són les ja al-ludides reiteracions de dades i conceptes (si bé, sens dubte, molt pitjor haurien sigut les absències, i més encara les contradiccions flagrants); per exemple, quan al darrer capítol del volum es torna a explicar quins són els territoris de la llengua catalana, $\mathrm{i}$ els diferents règims d'oficialitat que s'hi dóna (oficial a Andorra, cooficial en tres comunitats autònomes d'Espanya, no oficial a la resta, etc.), hom té la inevitable impressió de déja vu (i no una, sinó diverses vegades; tanmateix, s'hi pot respondre que no deixa de ser útil en el cas que un lector vagi directament a aquest capítol, i també que, des de la perspectiva de l'autora del text, la presentació d'aquestes dades preliminars li és útil, o fins necessària, per desenvolupar després el nucli central del seu tema; cert, possiblement). Els altres defectes, els del segon tipus, són uns detalls menors, certament molt menors (hom dirà que gairebé ridículs), però que tanmateix formen part d'allò que sí que s'hauria pogut (i fins convindria) evitar precisament en un llibre de múltiple autoria; es tracta, per exemple, d'un intangible tan subtil (car prové del punt de vista des del qual hom concep el llibre i s'hi enfronta durant la seva realització i la seva revisió, més que no pas del tema explícit del qual s'ocupa, ni de la seva materialització conscientment controlada) com són les denominacions. En podríem posar alguns altres exemples - pocs, per sortque resultarien més o menys paral-lels, però creiem que aquest (i així de passada portem l'aigua cap al nostre molí, o cap a un altre dels nostres molins acadèmics: l'onomàstica) illlustra prou bé el que estem intentant explicar. Anem a casos que parlen per si sols: no s'acaba d'entendre (i ens temem que un lector anglòfon o simplement foraster, internacional, ho entendrà encara menys) que un dels autors sigui professor «at the Open University of Catalonia» i que un altre treballi a «the Universitat Oberta de Catalunya»; i el mateix passa amb «University of Barcelona», «Autonomous University of Barcelona», «Pompeu Fabra University», «University of the Balearic Islands», «Rovira i Virgili University» (o també «Rovira Virgili University») i els corresponents noms en català: ara els uns, ara els altres... És evident que hauria calgut adoptar una versió (la que fos: les dues opcions són potencialment bones i en tot cas defensables) i aplicar-la al llarg de tot el llibre.

Semblantment simptomàtic d'una manca de revisió global en l'aspecte onomàstic (però una mica més greu, en la mesura que pot realment dur a no identificar diversos noms amb un mateix referent geogràfic i social) és el cas del territori que, entre altres denominacions (per exemple «Aragó catalanòfon»), coneixem 
des de fa unes dècades com a Franja de Ponent o la Franja (tout court). Doncs bé, sense que el fet sembli respondre a cap decantament ideològic (que hi hauria pogut ésser: notem, en tot cas, que ponent és just l'antònim de llevant, i que el punt de vista sempre conté implicacions), hi ha autors d'aquest llibre que hi al-ludeixen com a «Catalan-speaking Aragon», altres que ho descriuen com «the eastern strip of Aragon», altres que ho adapten directament com «the Franja de Ponent» $\mathrm{i}$ encara altres que ho redueixen a «la Franja» (també amb doble majúscula: «La Franja»), sense oblidar variants intermèdies com «La Franja” of Aragon» o el circumloqui «la Franja de Ponent, in Aragon»... Ignorem quin desxiframent en pot fer, de tot plegat, un lector anglòfon sense informacions suplementàries, però ens temem que existeix un elevat risc de confusió en aquest punt concret.

Valguin, doncs, aquests comentaris sobre uns aspectes que certament són anecdòtics com a mostra - en aquest cas crítica-del que, en termes generals, és just el contrari d'una crítica, sinó, com dèiem al principi, un dels dos principals valors d'aquest llibre: al costat del que és pròpiament el seu contingut —el de cadascun dels seus capítols i la suma de conjunt que en resulta- el fet mateix de ser, expressament, un producte sobre el català - ho diu la segona part del títol: the Case of Catalan- elaborat per a l'exportació, destinat a un públic internacional. Ja que aquest és, diguem-ho un cop més, l'encert estratègic d'editar el volum que ens ocupa en una colllecció de tant de prestigi acadèmic com és aquesta de Palgrave, amb tot el que això implica no sols de difusió sinó també d'auctoritas.

En tot cas, i per acabar, remarquem que això és el principal: el gran valor que ha suposat la publicació d'aquest llibre. Que és, com dèiem adés, un doble valor: d'una banda presenta una bona posada al dia de l'estat de la qüestió (té una lectura de profit també portes endins, doncs, encara que sigui en anglès) i, d'altra banda, ofereix a un públic potencial d'arreu del món, en anglès of course, un panorama clar, rigorós i força complet de la situació sociolingüística de la llengua catalana i de les polítiques lingüístiques de què és objecte des de fa dècades, en diferents sectors i desgranant convenientment els diferents territoris d'on és la llengua pròpia (i no sempre oficial, com es posa ben en relleu). Això, aquest doble valor, que hauria estat útil en tot moment $i$ circumstància, adquireix ara un interès especial, afegit, per causes que de ben segur no són tant intrínsecament sociolingüístiques (ni menys encara lingüístiques stricto sensu) sinó polítiques i fins i tot diríem que històriques (per dir-ho en una frase: és ara que el món mira cap a Catalunya que convé, més que mai, que la visió que se n'obtingui sigui certa, completa, fonamentada i enraonada). És evident. Però això, lluny d'arrossegar una crítica fàcil - demagògica - en termes d'oportunisme o de superficialitat, simplement fa que, just al contrari, en celebrem molt especialment l'aparició. Si aquest llibre no s'hagués fet, caldria urgentment posar-se a fer-lo. 